\title{
Serum Albumin Levels in Emergency Patients with Low BMI
}

\author{
Norihito Fukawa, Keiichi Yokoyama, Naoki Hashimoto, Yasuhide Kitazawa \\ Critical Care Medical Center, Kindai University Hospital, Osaka-Sayama, Japan \\ Email: kitaz@med.kindai.ac.jp
}

How to cite this paper: Fukawa, N., Yokoyama, K., Hashimoto, N. and Kitazawa, Y. (2018) Serum Albumin Levels in Emergency Patients with Low BMI. Open Journal of Emergency Medicine, 6, 21-26. https://doi.org/10.4236/ojem.2018.62004

Received: March 14, 2018

Accepted: June 5, 2018

Published: June 8, 2018

Copyright $\odot 2018$ by authors and Scientific Research Publishing Inc. This work is licensed under the Creative Commons Attribution International License (CC BY 4.0).

http://creativecommons.org/licenses/by/4.0/ (c) (i) Open Access

\begin{abstract}
A low body mass index (BMI) is often associated with low nutritional status and adverse health outcomes. While the BMI is used in describing "thinness" meaning cachexia, serum albumin levels were also used in assessing patient's nutritional conditions. Object: A retrospective study was conducted to determine whether the extremes of BMI and/or cachexia increased the morbidity and mortality in our critical emergency department. Methods: A hundred and five cases with low BMI $\left(\leq 18.5 \mathrm{~kg} / \mathrm{m}^{2}\right)$ were chosen from the patients who were admitted to our critical emergency department from Sept 2013 to Aug 2016. The relationship between serum albumin levels on admission and prognosis were analyzed. Results: No significant correlations were observed between body mass index and albumin levels in thin patients. Lower levels of serum albumin $(<3.3 \mathrm{~g} / \mathrm{dL})$ group was associated with a higher incidence of death. However, there was no death in higher levels of serum albumin $(\geq 3.3$ $\mathrm{g} / \mathrm{dL})$ group. A significant difference $(p<0.01)$ in life prognosis was observed in patients with albumin of $3.3 \mathrm{~g} / \mathrm{dL}$ or more and below. Moreover, the mean albumin level in septic cases was significantly lower than that of non-septic cases. Conclusions: Even with low BMI, if the albumin value was $3.3 \mathrm{~g} / \mathrm{dL}$ or more, the prognosis was good in our emergency department. Estimation of albumin level on admission is not only a simple and objective way to assess the nutritional status but also a useful outcome predictor of critically ill patients coming to emergency centers.
\end{abstract}

\section{Keywords}

BMI, Albumin, Cachexia, Sepsis

\section{Introduction}

A low body mass index (BMI) is often associated with low nutritional status and 
results in adverse health outcomes [1]. Low BMI may place the patient at risk for sarcopenia and functional debility [2]. Low nutritional status adversely affects mobility. Functional debility could potentially lead to hospitalization and ER visits and increased susceptibility to illness. One objective measure of low nutritional status is estimation of serum albumin. This study sought to investigate the relationship between underweight (BMI $\leq 18.5 \mathrm{~kg} / \mathrm{m}^{2}$ ), serum albumin, hospitalization and prognosis in our emergency department.

\section{Material and Methods}

The total number of patients who were admitted to our critical emergency department was 1024 from September 2013 to August 2016. The number of cases was 476, excluding children (under 15 years old), cases discharged within 24 hours include early death or early walk-out, cases without appropriate data and cases of trauma out of these 1024 patients. BMI varied from 9.3 to 44.8 (median: 22 ) in these 476 cases. Among those 476 cases, 105 patients (22.1\%) were assessed as thin and were analyzed in this study. The BMI is defined as the weight in kilograms divided by the height in meters squared (weight $/$ height ${ }^{2}\left[\mathrm{~kg} / \mathrm{m}^{2}\right]$ ). Low BMI was defined as under $18.5 \mathrm{~kg} / \mathrm{m}^{2}$ in this study.

The correlations between serum albumin and BMI were analyzed using Spearman's correlation test. The relationship between serum albumin and prognosis in thin patients $\left(B M I \leq 18.5 \mathrm{~kg} / \mathrm{m}^{2}\right)$ was analyzed using Fischer's test. The comparison of serum albumin in patients with and without sepsis was analyzed using Mann-Whitney's U test.

\section{Results}

1) Outline of thin patients (Table 1 ).

A total 105 patients ( 55 male and 50 female) were included and their age varied from 17 to 95 (median: 73) years old. The length of stay varied from 3 to

Table 1. Profile of thin patients.

\begin{tabular}{ll}
\hline Number of patients & 105 \\
Age & $17-95$ years old (median: 73$)$ \\
Gender & male 58, female 47 \\
Hospitalization period & $3-150$ days (median: 13) \\
Death within 4 weeks after admission & $15(14.3 \%)$ \\
Main illness (number of patients died) & \\
Sepsis & $28(7)$ \\
Out-of-hospital cardiac arrest & $20(5)$ \\
Intoxication & $20(0)$ \\
Digestive truct disease & $11(1)$ \\
Others & $26(2)$
\end{tabular}


150 (median: 13) days. Fifteen (14.3\%) patients died within 4 weeks of admission. Seven of 28 cases of sepsis, 5 of 20 cases with out-of-hospital cardiac arrest, none of 20 cases of intoxication, 1 of 11 cases of digestive disease, and 2 of 26 cases other than above died before 4 weeks after admission.

2) Serum albumin levels in thin patients are shown in Figure 1.

The level of serum albumin on admission varied from 1.1 to 5.5 (mean: 3.3 $\mathrm{g} / \mathrm{dL}$ ). No significant correlations were observed between BMI and serum albumin levels. Fourteen cases (13.2\%) died within 4 weeks after admission (red dots in Figure 1).

3) Serum albumin levels and life prognosis in thin patients (Table 2).

Lower levels of serum albumin $(<3.3 \mathrm{~g} / \mathrm{dL})$ group was associated with a higher incidence of death, $14 / 50$ cases $(28 \%)$. However, there was no death in higher levels of serum albumin ( $\geq 3.3 \mathrm{~g} / \mathrm{dL})$ group, 0/55 case $(0 \%)$. A significant difference $(p<0.01)$ in life prognosis was observed in patients with albumin of 3.3 $\mathrm{g} / \mathrm{dL}$ or more and below.

4) Serum albumin level in sepsis and non-sepsis (Figure 2).

Albumin level in 28 septic cases (mean \pm SD; $2.79 \pm 0.92$ ) was significantly lower than that of 77 non-septic case (mean $\pm \mathrm{SD} ; 3.57 \pm 0.79$ ).

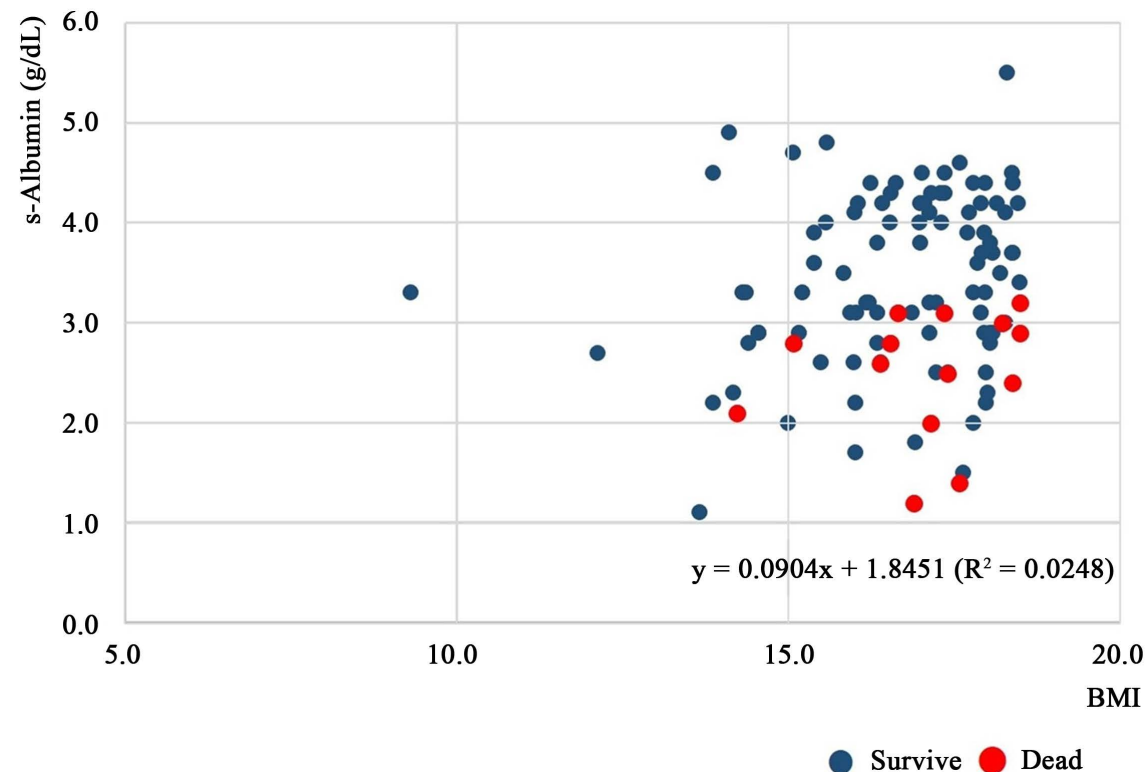

Figure 1. Serum albumin and BMI in patients with low BMI.

Table 2. Serum albumin levels and prognosis in thin patients.

\begin{tabular}{cccc}
\hline Serum albumin & Survive & Dead & SUM \\
\hline$\geq 3.3 \mathrm{~g} / \mathrm{dL}$ & 55 & 0 & 55 \\
$<3.3 \mathrm{~g} / \mathrm{dL}$ & 36 & 14 & 50 \\
SUM & 91 & 14 & 105
\end{tabular}

$p<0.01$, Fischer's test. 


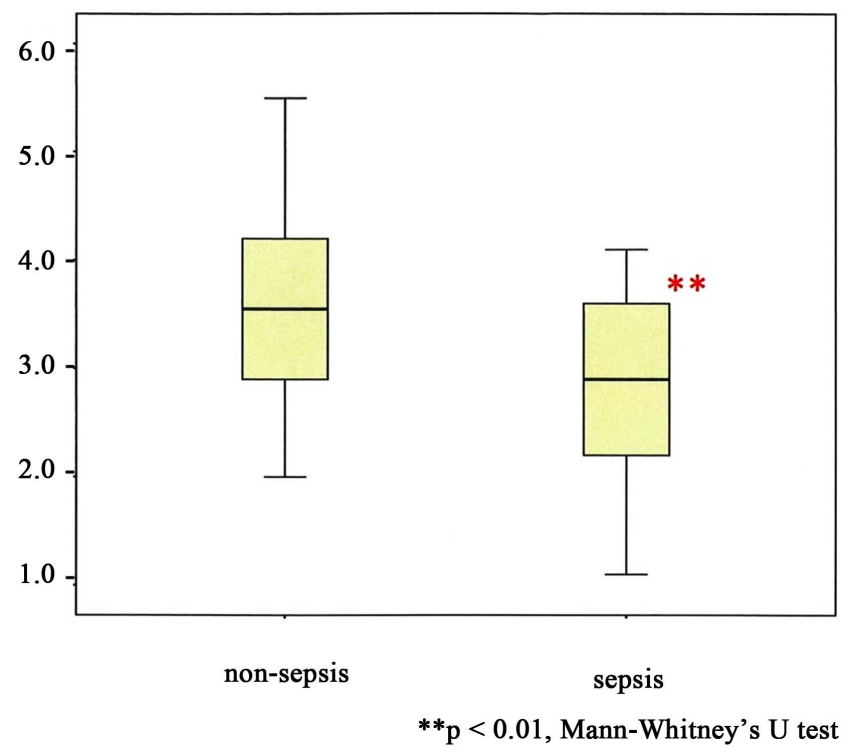

Figure 2. Serum albumin in thin patients with and without sepsis.

\section{Discussion}

Loop et al. reported that thin patients might be at a higher risk after coronary artery operations [3]. The extremes of body mass index and cachexia increased the morbidity and mortality associated with operations. Body mass index was used to objectively measure "thinness". Albumin is the main serum protein of human beings, which is synthesized by the liver from amino acids [4]. Normal levels of serum albumin can maintain the colloid osmotic pressure of plasma and prevent the development of tissue edema. The concentration of serum albumin is often decreased in a great deal of conditions, for example, in major surgery, trauma or infection.

Sepsis, a severe infection, is also frequently accompanied by hypoalbuminemia, which is known to be caused by decreased hepatic synthesis of albumin, increased leakage into the interstitial compartment, and persistent catabolism [5]. According to the results in this study, albumin levels in patients with sepsis were significantly lower than that of non-septic cases.

The low level of serum albumin often leads to the diagnosis of malnutrition. However, judging from the results that the level of serum albumin was not so low even in thin patients, hypoalbuminemia does not mean malnutrition directly. It suggests that the major cause of hypoalbuminemia is the leakage of albumin from blood vessels due to systemic inflammation, especially in cases with sepsis. This phenomenon is called capillary leak syndrome [6].

Several studies have reported that the incidence of hypoalbuminemia was about $60 \%-80 \%$ in critically ill patients [7] [8]. Hypoalbuminemia was defined as less than $3.3 \mathrm{~g} / \mathrm{dL}$, and in this study, the incidence rate was $52 \%$ (55/105). This study revealed the independent risk factors of hypoalbuminemia in emergency patients with low BMI. It shows that patients with albumin level $<3.3 \mathrm{~g} / \mathrm{dL}$ had much worse prognosis than that of albumin level $\geq 3.3 \mathrm{~g} / \mathrm{dL}$. 
An albumin level of $3.3 \mathrm{~g} / \mathrm{dL}$ can be a threshold point for life prognosis. Hypoalbuminemia influences morbidity and mortality by adversely affecting various organ functions, the immune system, and wound healing [9]. Research has shown that malnutrition increases postoperative complications by delaying wound healing and increasing infection rate [10] [11]. The low cost of serum albumin assays and hypoalbuminemia, monitoring albumin levels has been advocated as a prognostic tool in predicting high risk patients visiting emergency department.

\section{Conclusion}

There were no significant correlations between BMI and albumin levels. Even with low BMI, if the albumin value was above $3.3 \mathrm{~g} / \mathrm{dL}$, the prognosis was good in emergency department. Hypoalbuminemia does not mean malnutrition directly. Estimation of albumin level on admission is a simple and objective way to assess the general status and to predict prognosis of critically ill patients with low BMI coming to emergency centers.

\section{References}

[1] RingbackWeitoft, G., Eliasson, M. and Rosen, M., et al. (2008) Underweight, Overnight and Obesity as Risk Factors for Mortality and Hospitalization. Scandinavian Journal of Public Health, 36, 169-176. https://doi.org/10.1177/1403494807085080

[2] Inzitari, M., Doets, E., Bartali, B., et al. (2011) Nutrition in the Age-Related Disablement Process. The Journal of Nutrition, Health \& Aging, 15, 599-604. https://doi.org/10.1007/s12603-011-0053-1

[3] Loop, F.D., Golding, L.R., Macmillan, J.P., et al. (1983) Coronary Artery Surgery in Women Compared to Men: Analysis of Risks and Long-Term Results. Journal of the American College of Cardiology, 1, 383-390. https://doi.org/10.1016/S0735-1097(83)80064-3

[4] Gatta, A., Verardo, A. and Bolognesi, M. (2014) Sepsis-Associated Hyperlactatemia. Critical Care, 18, 503-513. https://doi.org/10.1186/s13054-014-0503-3

[5] Nicholson, J.P., Wolmarans, M.R. and Park, G.R. (2000) The Role of Albumin in Critical Illness. British Journal of Anaesthesia, 85, 599-610. https://doi.org/10.1093/bja/85.4.599

[6] Siddall, E., Khatri, M. and Radhakrishnan, J. (2017) Capillary Leak Syndrome: Etiologies, Pathophysiology, and Management. Kidney International, 92, 37-46. https://doi.org/10.1016/j.kint.2016.11.029

[7] Aguayo-Becerra, O.A., Torres-Garibay, C., Macías-Amezcua, M.D., et al. (2013) Serum Albumin Level as a Risk Factor for Mortality in Burn Patients. Clinics (Sao Paulo), 68, 940-945. https://doi.org/10.6061/clinics/2013(07)09

[8] Gatta, A., Verardo, A. and Bolognesi, M. (2012) Hypoalbuminemia. Intern Emerg Med, 7, S193-S199. https://doi.org/10.1007/s11739-012-0802-0

[9] Sullivan, D.H., Sun, S. and Walls, R.C. (1999) Protein-Energy Undernutrition among Elderly Hospitalized Patients: A Prospective Study. JAMA, 281, 2013-2019. https://doi.org/10.1001/jama.281.21.2013

[10] Sungurtakin, H., Sungurtakin, U., Barci, C., et al. (2004) The Influence of Nutritional Status on Complications after Major Intraabdominal Surgery. Journal of the 
American College of Nutrition, 23, 227-232.

https://doi.org/10.1080/07315724.2004.10719365

[11] Schiesser, M., Müller, S., Kirchhoff, P., et al. (2008) Assessment of a Novel Screening Score for Nutritional Risk in Predicting Complications in Gastro-Intestinal Surgery. Clinical Nutrition, 27, 565-570. https://doi.org/10.1016/j.clnu.2008.01.010 